\title{
Los carteles del periódico Tierra: construcción de la identidad del obrero colombiano*
}

\author{
Victoria Eugenia Peters ${ }^{* *}$
}

\begin{abstract}
RESUMEN
Recibido: 4 de septiembre de 2013

Este trabajo pretende hacer una revisión del periódico Tierra,

Evaluado: 20 de septiembre de 2013 órgano central del Partido Comunista, en el periodo comAceptado: 7 de octubre de 2013 prendido entre 1932 y 1939. Esta publicación se configuró como dispositivo de enunciación articulado con las actividades de un proyecto político que empezó a surgir en la década de 1930. La revisión incorpora una mirada analítica de algunas de las imágenes de dicho periódico, realizadas en xilografía y aplicadas a carteles políticos.

Palabras clave: cartelismo político, comunismo, poder, grabado, xilografía.
\end{abstract}

* Artículo de reflexión que expone los resultados de un proyecto de investigación sobre procesos discursivos desarrollado en la Maestría en Semiótica de la Universidad de Bogotá Jorge Tadeo Lozano.

** Estudiante de la Maestría en Semiótica de la Universidad de Bogotá Jorge Tadeo Lozano. Especialista en Pedagogía del Diseño por la Universidad Nacional de Colombia. Profesional en Diseño Gráfico por la Universidad de Bogotá Jorge Tadeo Lozano. Actualmente es docente de cátedra de la Universidad de Bogotá Jorge Tadeo Lozano. Correo electrónico: victoriae.peters@utadeo.edu.co 


\section{The cartels of the newspaper Tierra: construction of the identity of the Colombian worker}

\section{Abstract}

This work a review of the newspaper tries to do Tierra, Central Organ of the Communist party, in the period understood betEvaluated: September 20, 2013 ween the year 1932 to 1939, device of statement that was articuAccepted: October 7, 2013 lated to the activities of a political project that started arising in the decade of 1930. The review incorporates an analytical look of some of the images of the above mentioned newspaper, realized in xylography and applied to political cartels.

Keywords: political posters, communism, power, engraving, xylography. 


\title{
Os cartazes do jornal Tierra:
}

\section{construção da identidade do trabalhador colombiano.}

\begin{abstract}
Resumo
Recebido: 4 de setembro de 2013

Avaliado: 20 de setembro de 2013

Aceito: 7 de outubro de 2013

Este trabalho quer fazer uma revisão no jornal Tierra, órgão central do Partido Comunista, no período compreendido entre 1932 e 1939. Esta publicação conformou-se como dispositivo de enunciação articulado com as atividades de um projeto político que começou a surgir na década de 1930. A revisão inclui um olhar analítico de algumas das imagens desse jornal, realizadas na xilografia e aplicadas aos cartazes políticos.

Palavras-chave: cartaz político, comunismo, poder, gravado, xilografia.
\end{abstract}




\section{INTRODUCCIÓN}

Tierra, un periódico de circulación nacional e internacional, comenzó a publicarse en 1932, es decir, dos años después de la creación de Partido Comunista Colombiano. Vale la pena señalar que la prensa o el discurso periodístico, que es a la vez discurso político, en un contexto de resistencia e invisibilidad, fue acogida rápidamente como órgano coadyuvante frente a un orden político, social y discursivo dominante-hegemónico. El surgimiento de Tierra en un contexto de dominación (lucha de clases para los marxistas) implicó la oportunidad de transmitir - como corresponde a un dispositivo de enunciación - códigos y reglas de comportamiento para la sobrevivencia, en un contexto de asimetría frente a los grandes dispositivos dispuestos por el orden dominante, es decir, el orden capitalista y burgués ${ }^{1 .}$

De tener una frecuencia diaria y contar con entre cuatro y ocho páginas en 1932, en 1938 pasó a circular semanalmente, cambiando a partir del número 149 a ocho páginas; adicionalmente, en marzo de 1938 se publicó una edición especial de 32 páginas $^{2}$. La disminución de su periodicidad refleja la poca capacidad de maniobra de sus autores, lo que reforzó la imposibilidad de constituirse en un dispositivo abierto y conservó su condición de dispositivo cerrado y resuelto para una minoría que, aun así, recibía de manera permanente la referencia a códigos

1 Entendemos por dispositivo un mecanismo de normalización y normatividad de conductas y de disciplinas. El discurso sobre cualquier episteme o sobre cualquier práctica es un dispositivo.

2 Esta edición del periódico Tierra se llamó "La edición antifascista de Tierra, como la más clara expresión de la democracia colombiana", donde se evidencian las posturas antifascistas de liberales y conservadores, entre otros. que apuntaban a consolidar una unidad. Esta situación parte del hecho de que tanto el lenguaje verbal escrito como el gráfico conforman una unidad discursiva en la que se considera al lector como interlocutor aliado, pero también como posible objeto de transformación. Entonces, la reiteración de términos que hacen parte del extenso glosario comunista, como también la comunicación de una estética particular, hacen de este dispositivo un todo que comunica unidad significativa $y$, por lo mismo, intervención en un juego que implica relaciones de poder.

Este trabajo de investigación tuvo como punto de partida la revisión del periódico impreso de los años 1932 y 1938, al igual que de sus copias digitalizadas que cubren el periodo 1933-1939. En la totalidad de las páginas se identifican los diferentes términos y apelaciones que se hacen del comunismo como proyecto ideológico: se interpela de manera permanente a la clase trabajadora; se busca consolidar una disciplina de partido (llamamientos a lo que todo comunista debe hacer); asimismo, dada la condición de desventaja (asimetría) económica, hay pedidos para el apoyo y sostenimiento del periódico $\mathrm{y}$, naturalmente, denuncias del maltrato hacia la clase obrera, como reflejo de una relación de dominación. Lo anterior es en lo concerniente al lenguaje escrito. En relación con el aspecto gráfico, el periódico reconoce en la fuerza del cartel la posibilidad de crear un significado discursivo, en cuanto apoya ya no desde lo verbal sino desde una iconografía particular el proyecto ideológico comunista, que surge desde abajo (clase obrera) y no desde arriba (burguesía). En este último sentido, el periódico combina un discurso verbal y una estética gráfica para lograr una unidad 
discursiva que busca enunciar la ideología en su totalidad.

Se espera, en el caso particular de las imágenes del periódico Tierra, encontrar la influencia de la iconografía europea propia de la primera posguerra, del surgimiento de los fascismos, de la avanzada roja (posterior a la Revolución bolchevique) y de la guerra civil española. Todos estos referentes, enmarcados en un contexto nacional de fin de la hegemonía conservadora y surgimiento de partidos de izquierda.

Los trabajos del pensador alemán Reinhardt Koselleck (1923-2006) sobre unidad política bien pueden orientar en dos sentidos nuestra comprensión del periódico: por el llamado que hace a revisar la iconografía como recurso político para el reconocimiento de los oprimidos y por el papel que desempeña la búsqueda de unidad en uno de los propósitos que tiene la comunicación en el campo ideológico: la alta recordación. Al hablar de partidos y de los medios de comunicación que los soportan, es pertinente apelar al siguiente concepto que el autor desarrolla, a propósito de la categoría de la unidad política:

Una unidad social o política de acción se constituye solo mediante conceptos en virtud de los cuales se delimita y excluye a otras, es decir, en virtud de los cuales se determina a sí misma. [...] Siempre se exigen conceptos en los que un grupo se debe reconocer y determinar a sí mismo. [...] Corresponde a la peculiaridad del lenguaje político que sus conceptos se refieran a unidades de acción, a instituciones, grupos, etc., y a sus movimientos, pero también que no se fusionen con ellos.

(Koselleck, 1993, 206)

\section{LA UNIDAD POLÍTICA EN EL PERIÓdICO TIERRA}

A continuación intentaremos articular el concepto deleuziano de dispositivo y el de unidad política de Koselleck para interpretar la identidad del periódico Tierra. En relación con el concepto de unidad política podemos apuntar a dos frentes: desde su discurso verbal y gráfico, el periódico atiende los intereses de una unidad política que es el Partido Comunista. En ese sentido, desempeña el papel de dispositivo de enunciación de este, es decir, sirve a sus intereses; estos son los de organización, militancia política, disciplina, normalización (obediencia a la normas) de las masas en torno a un proyecto ideológico y, como es natural en un contexto de dominación, supervivencia. En otras palabras y siguiendo a Koselleck, Tierra es el órgano de expresión de una unidad política o colectividad agrupada por una ideología, donde ideología implica valores, fines, medios. Como dispositivo de enunciación, busca movilizar a sus lectores en torno a un plan programático, a un proyecto de sociedad, a los llamamientos, pedidos y denuncias con los que establece distancias frente al quehacer de otros grupos políticos (Liberal y Conservador).

El discurso es un elemento que garantiza unidad. Koselleck lleva al límite la concepción de Foucault sobre el discurso como tejido, como malla que integra otras mallas discursivas, al plantear que esa malla discursiva es compacta; es decir, la unidad política tiene unos conceptos que se distribuyen 
en un grupo de agentes y a quienes les son comunes esos conceptos. Koselleck, concentrado en el estudio de los lenguajes políticos, indica que estos conllevan acciones: los discursos comunican y se asocian a un plan programático que busca un logro máximo: el poder. Con su lenguaje verbal y gráfico, Tierra, como dispositivo de enunciación del Partido Comunista, se articula con esa búsqueda: disciplina, ordena y transmite valores que apuntan al objetivo de organizar las masas para alcanzar el poder. Lo verbal y lo gráfico se aúnan para alcanzar ese propósito.

\section{Conceptos contrarios ASIMÉTRICOS}

Koselleck rastreó algunas experiencias y conceptos de diferentes periodos de la llamada Modernidad y los comparó con otros momentos de la historia; de hecho, Koselleck recurrió a datos sociohistóricos y analizó testimonios lingüísticos para, finalmente, proporcionar elementos que permitieran construir una teoría de los tiempos históricos, apelando a la semántica para seguir las huellas de la transformación de la historia. Con Koselleck es posible problematizar las representaciones discursivas de la política a partir del carácter tanto polisémico como polémico de la nación, espacios en los cuales conviven formas distintas de experimentar lo político (entendido como pugna por el poder y determinado por la condición de asimetría ${ }^{3}$.

3 Al estudiar la historia, Kosellek introdujo el concepto de asimetría como una coordinación desigualmente contraria a lo ya establecido. Por lo general, se aplica de forma unilateral por algo o por alguien. Aquí se puede comenzar a hablar del concepto de lo contrario asimétrico, presente a lo largo de la historia de la humanidad.
Entre los "conceptos contrarios" estudiados por Koselleck está el de la dualidad helenobárbaro, la cual ocupa indudablemente un lugar preferencial si se considera que uno de sus componentes, el término bárbaro, es aplicable hasta hoy, en general, tanto en el lenguaje científico como político, mientras que la expresión heleno, que originalmente determinaba a bárbaro en forma negativa, ya no sobrevive más que históricamente o como nombre concreto de una civilización. Por eso, aunque esta comparación clásica ya no es actual, muestra rasgos modélicos que emergen siempre y constituyen un elemento profundamente arraigado en el imaginario de Occidente.

Al profundizar en lo anterior, es posible afirmar lo siguiente: con los griegos y su invención del bárbaro se inicia para Occidente un modo de concebir, inventar e inventariar a los demás, que, cabe añadir, son considerados "distintos" a lo que es ya conocido y que la sociedad ha aceptado y establecido. La dualidad heleno-bárbaro es un escalón fundamental en la larga lista de conceptos contrarios asimétricos que sentará las bases para las posteriores oposiciones romano-bárbaro, civilizado-bárbaro, occidental-oriental y, para nuestro caso, derecha-izquierda y opresor-oprimido. La continuidad de esta afirmación lingüística - que, a su vez, se presenta como conducta histórica y con el paso del tiempo se convierte en condición humana - se da cuando el concepto de heleno cambia por el de cristiano. Al analizar los sucesos históricos, es común observar los términos de esta nueva dualidad convertidas en calificativos otorgados por un sector de la sociedad a otra. En términos de Foucault, podemos hablar también de discursos de verdad en 
los cuales los bárbaros serán invisibilizados por dispositivos de enunciación. La resistencia de los vencidos, de los anormales, de las izquierdas, de los bárbaros e incivilizados se expresarán con dispositivos de resistencia que también pretenderán construir unidades discursivas convincentes.

\section{Una mirada a Colombia}

Estas formas de exclusión cultural, social y política, determinadas por la condición de "contrarios" y de las asimetrías existentes entre ellos, se trasladan también a la historia colombiana. No es difícil percibirlo al hacer un rastreo de prensa del siglo xx. La conformación, en el país, de un sistema político basado en una concepción de estado liberal condujo necesariamente al surgimiento de partidos políticos y su consecuente organización de grupos de interés y búsqueda del poder. Los enfrentamientos partidistas entre liberales y conservadores han alimentado una violencia que viene desde mediados del siglo xix y llega con matices y agravantes hasta nuestros días.

El terreno simbólico ha servido de dispositivo de enunciación a aquellas pugnas. Hoy el discurso es cada vez más refinado en ese sentido. El punto por resaltar es que por medio de símbolos, traducidos por ejemplo en colores, estos partidos lograron provocar en distintos sectores sociales un sentimiento de pertenencia y unidad. Por eso, se convirtió en algo común diferenciar a los afiliados del Partido Liberal como los "rojos" o "cachiporros", y a los del Conservador como los "azules" o los "godos". Ambos apuntaron a un propósito: la toma del poder. A ese dispositivo de enunciación subyacen otros dispositivos menos visibles, más entramados, como el clientelismo: los políticos otorgan beneficios temporales a los electores a cambio de sus votos. En una lógica de contrarios se oponen azul y rojo. En una lógica de asimetría gana quien logre mayores votos, aun a costa de la verdad y la transparencia. Los contrarios no son siempre unívocos en su actuar. El poder hunde sus raíces en lugares insospechados (como indica Foucault, el poder es capilar) y, en esa medida, el brote en otro lugar del globo (la uRss) de otro modelo de sociedad implicó lentamente el surgimiento de otros "contrarios" y de líneas de fuga, rupturas ideológicas y florecimientos de nuevas alianzas y sectores de ideologías alternas.

En ese sentido surgen para las multitudes nuevos dispositivos de enunciación que intentan captar su atención y reclutarles para su causa. Tierra irrumpe frente a un bipartidismo excluyente y finalmente más cercano a los intereses de las clases burguesas. Es un dispositivo que se constituye a sí mismo en línea de fuga y se lanza en esa aventura a crear una nueva propuesta gráfica, distinta a la que el país ha vivido con el bipartidismo.

\section{REPASO AL BIPARTIDISMO Y EL SURGIMIENTO DE LOS MOVIMIENTOS SINDICALISTAS en Colombia}

En el caso colombiano, los primeros pasos para establecer los ideales sociales enfocados desde la ideología de izquierda iniciaron a mediados de la década de 1920. Su carácter social define su accionar colectivo y no 
individual, pero abarcan una parte de la sociedad con la que se identifican; las agrupaciones pueden ser locales, regionales o nacionales. Para hablar de movimiento social se requiere que esas formas de acción colectiva permanezcan en el tiempo y que no se confundan con estallidos sociales espontáneos y fugaces. No están en permanente acción, pueden tener periodos de latencia, estar incluso inactivos u ocultos por años en relación con el ámbito social y político, para luego resurgir cuando el momento lo amerite ${ }^{4}$.

Como en el contexto internacional, en Colombia se generó un espacio para el surgimiento de los ideales comunistas o de izquierda, los cuales representaron una alternativa para la población frente a los partidos tradicionales. El Partido Comunista de Colombia se fundó el 17 de julio de 1930 a partir de la convergencia de grupos intelectuales cercanos a la Revolución de Octubre (1917) y de la mayor parte de los militantes obreros del antiguo Partido Socialista Revolucionario (PSR) de la década de 1920. La falta de una línea unificada en el PSR llevó a que el ala más radical (donde figuraban los gremios de artesanos, las federaciones de obreros portuarios y del transporte y las nacientes ligas agrarias e indígenas) aceptara las 21 condiciones de ingreso

4 No son pocos los antecedentes nacionales e internacionales que precipitan el surgimiento de movimientos obreros de izquierda. La explotación de materias primas a manos de capital extranjero y bajo formas acaso esclavistas de relación laboral, la exclusión de sectores populares en los juegos bipartidistas de poder, la subasta de bienes nacionales a la inversión extranjera, el surgimiento de un proletariado que venía a engrosar los cinturones de miseria urbanos tras la pérdida de sus tierras y, finalmente, el uso de las Fuerzas Armadas para perseguir y reprimir intentos de demandas sociales (la masacre de las bananeras, por ejemplo) fueron algunos factores en los que se sintetizó la lucha de contrarios y fue evidenciándose la fuerte asimetría entre unos sectores que buscaban quedarse con el poder y otros que empezaban a organizarse para alcanzarlo tras haber sido excluidos sistemáticamente. Vendrían entonces los intentos de sindicalización obrera y el surgimiento de partidos de izquierda. (Archila, 1992). a la Internacional Comunista. Cabe resaltar el carácter de su ideología, basado en el marxismo-leninismo surgido en Rusia posterior al derrocamiento del Imperio y al establecimiento del comunismo, como resultado de la Revolución bolchevique ${ }^{5}$. Si bien estos ideales no tuvieron acogida entre la mayoría de la población, al menos sí encontraron eco en una fracción del partido liberal de mediados del siglo $\mathrm{xx}^{6}$.

\section{Tierra}

El periódico Tierra, órgano oficial del Partido Comunista Colombiano, afirma en su primer editorial que "ha visto la luz pública desde el primero de agosto (de 1932), de acuerdo con nuestras promesas y tras vencer las más angustiosas dificultades", para analizar el acontecer mundial y nacional, desde la óptica de la lucha de clases marxista y con artículos de escritores nacionales e internacionales.

Dirigido por el jurista e historiador Guillermo Hernández Rodríguez, secretario del Partido y quien se había formado inicialmente en el Partido Liberal, el periódico

5 Las condiciones para la admisión a la Internacional Comunista, popularmente conocidas como las 21 condiciones o los 21 puntos eran los puntos ideológicos y organizativos que debía aprobar todo partido u organización que quisiese adherirse a la Internacional Comunista. Estas condiciones fueron aprobadas durante el II Congreso Mundia de la Internacional Comunista, celebrado el 30 de julio de 1920.

6 Por otra parte, en 1932, el caudillo liberal Jorge Eliécer Gaitán creó el movimiento popular Unión Nacional Izquierdista Revolucionaria (unir), cuyo fin era impulsar algunas demandas de corte social en la Constitución. El movimiento atrajo a los sectores populares, representados principalmente por los campesinos y obreros, pero sembró desconfianza dentro de las clases dirigentes de los partidos tradicionales debido al contenido socialista de algunas de las propuestas de su líder, como, por ejemplo, una mejor distribución de la riqueza y la búsqueda de una sociedad más equitativa. Para Gaitán, el Partido Liberal debería liderar esas reformas en el marco de las ideas socialistas y dentro de los límites de la democracia. Revista Credencial Historia No. 109. Enero 1999. 
tuvo como jefe de redacción al poeta Luis Vidales, quien con su pluma inició su participación en el periódico adelantando una enérgica campaña contra la guerra colombo-peruana en $1928^{7}$.

En los primeros tres años de su publicación, predomina en el periódico matutino el texto abigarrado, con diferentes usos tipográficos en sus secciones, acompañado con algunas fotografías, ilustraciones y caricaturas. Pero en 1935, el discurso eminentemente verbal empieza a conjugarse con el gráfico, incorporando en primera plana, al lado del cabezote y en algunas de las páginas interiores, linóleos de artistas como Gonzalo Ariza y algunas caricaturas de Ricardo Rendón. Después de 1937, cuando aparece el cargo de director artístico, la imagen adquiere un papel preponderante como respaldo del discurso de resistencia con el que, desde su creación, Tierra se rebela ante las políticas del gobierno.

Como lo anunciamos al inicio de este documento, intentaremos develar cómo la imagen desempeña un papel importante para articularse con otros elementos del periódico y lograr unidad como dispositivo de enunciación (figura 1): la imagen misma, la caricatura, el color, su público (quién lo compra), cómo la imagen contribuye a su conexión con otros dispositivos y movimientos artísticos de otros

7 No obstante su esfuerzo por arraigarse en la sociedad colombiana como una alternativa política al bipartidismo ya establecido, el Partido Comunista Colombiano no lo consiguió en la primera mitad del siglo xx. El tono directo de sus contenidos y las continuas invitaciones a denunciar los maltratos y atropellos a la clase trabajadora suscitó que Tierra acabara siendo atacado por las turbas: sus instalaciones fueron destruidas y su director terminó por adherirse al movimiento político liberal de Jorge Eliécer Gaitán, en cuanto su ideología liberal se acercaba en varios conceptos a la ideología comunista. Tomado de http://luisvidales.blogspot.se/2007/01/esbozo-biogrfico.html países, que en ese momento comparten su posición ideológica y evidenciará el proceso de movilidad del dispositivo en el país.

Figura 1. Página del periódico Tierra, número 1, agosto 2 de 1932, p. 1

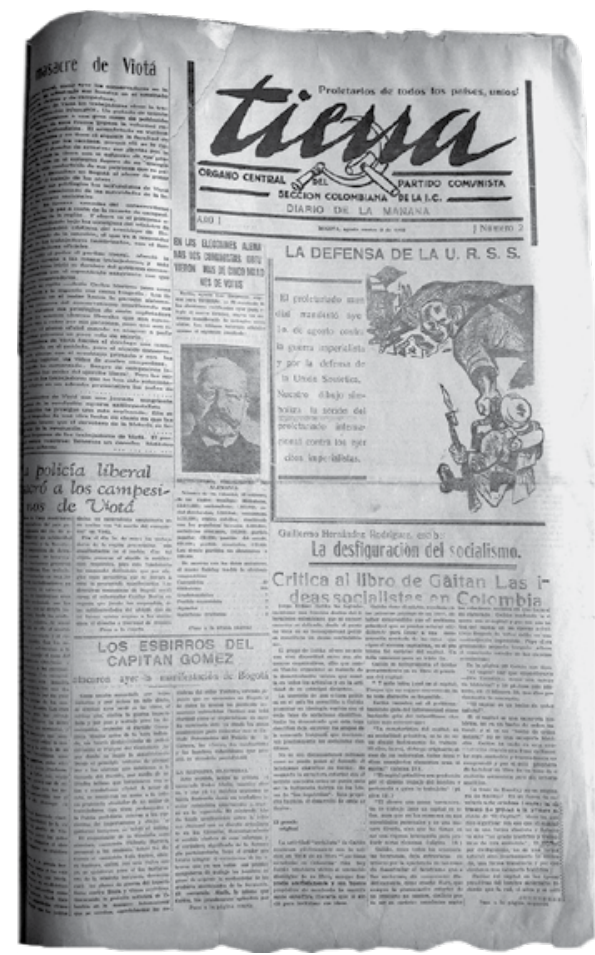

Fuente: Biblioteca Nacional de Colombia

\section{Luis Efraín Gómez Leal: xilografías que leen ${ }^{8}$}

Con el desarrollo del grabado se podía superar el inconveniente de la obra única y facilitar el acceso de muchos a una sola imagen. En el resurgimiento de la gráfica es evidente que los colombianos siguieron las pautas del movimiento mexicano, cuyos

8 La xilografía es una técnica de impresión en relieve realizada sobre una matriz de madera. La diferencia fundamental con el linóleo es que la veta de esta se aprecia al ser estampada, realzando la belleza de la imagen. 
pintores más destacados, como David Alfaro Siqueiros (1896-1974), Diego Rivera (1886-1957) y Xavier Guerrero (1894-1974), alcanzaron vastos sectores populares con las xilografías que divulgaban a través del semanario del Sindicato de Pintores, Escultores y Grabadores Revolucionarios de México, El Machete (1923-1925) (Troconi, 2010). En nuestro país, durante los años treinta renació la obra gráfica a la par que surgían nuevas ideologías políticas, en franco receso desde el impulso que entre 1880 y 1890 le dieran publicaciones como el Papel Periódico Ilustrado o El Zancudo.

Gonzalo Ariza (1912-1995) y Luis Efraín Gómez Leal (c. 1962) fueron los artistas colombianos que en los años treinta practicaron el grabado, y si bien prefirieron la xilografía y la lineografía, su producción no fue numerosa. Al detenernos en su temática, la obra gráfica que realizaron en los años treinta tiene marcada tendencia popular y política, pues fue concebida, en su mayoría, para acompañar textos de denuncia. Las primeras lineografías de Ariza aparecieron en 1934 en el periódico El Bolchevique y posteriormente en las ediciones del periódico Tierra de los años 1935, 1936 y 1937.

Gómez Leal no solo fue ilustrador en dicho periódico (desde 1937 con la aparición de la historieta "Juan Pueblo"), sino que también ejerció como su director artístico desde 1938. En Tierra, su obra es la del activista que concibe su trabajo en función de las necesidades de agitación y propaganda de un partido. Es el artista que no solo mira su mundo interior, se considera ejemplo de lo que Antonio Gramsci llamó intelectual orgánico: un pensador y creador para la transformación social y política (Medina, 1995). En ese sentido empieza a vislumbrarse como una línea de fuga en un modelo que no acoge aún propuestas democráticas de participación abiertas a los sectores populares. Así, trabajó linóleos y maderas con temas estrictamente ligados a los acontecimientos políticos del momento. Lo más destacado de su obra gráfica está conformado por los carteles xilográficos que Tierra insertaba en las primeras páginas e iba incorporando a su intención comunicativa y política (figura 2). Otras de las imágenes encontradas en las páginas enfrentadas tenían el carácter de acompañar la información y destacar la sección donde se encontraban.

Figura 2. Doble página del periódico Tierra, número 154, marzo 13 de 1938, pp. 12-13

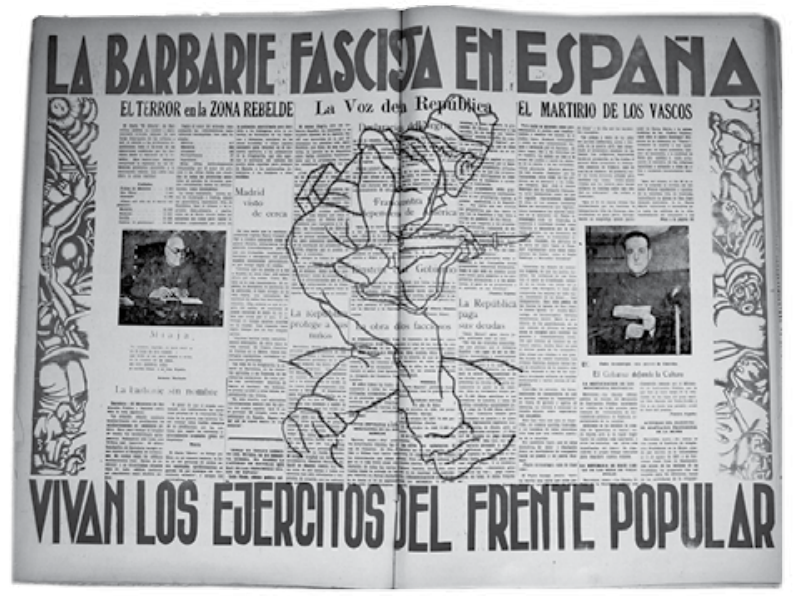

Fuente: Biblioteca Nacional de Colombia

Los carteles de Gómez Leal se caracterizan por los acentos dramáticos en su composición y en la expresión de las figuras masculinas, con marcado contraste entre zonas blancas y negras. A todo esto se le agrega que el conjunto es plano, aunque 
haya cambios de escala que alteran las dimensiones de lo que está atrás con respecto a lo que está adelante. En lo plástico el resultado final es claro, simple y esquematizado. Esta composición facilitaba la reproducción en un papel de baja calidad y generaba un impacto marcado frente a las fotografías que presentaban irregularidad en la apariencia de la tinta. La intención de provocar una comunicación hacia sectores populares, analfabetas aún, quizás requería de una alta recordación desde la imagen, de una claridad diáfana entre contrarios: trabajadores y burgueses, opresores y oprimidos, masas obreras e individualistas burgueses.

En los carteles que se muestran a continuación, en el mismo orden en que fueron publicados, se evidencia cómo la construcción final del comunista o del trabajador colombiano de este periodo tiene sus raíces en las imágenes europeas, específicamente en las españolas. En parte, ello se explica porque el comunismo se concibió como ideología internacional: si el capitalismo es global, la clase obrera también lo es. La similitud de obreros franceses, alemanes o rusos con los colombianos y latinoamericanos está dada porque sufren la misma condición: dominación. La similitud de estilos se mira sin prejuicio gracias a que el comunismo es internacional.

Los carteles son una selección de xilografías reproducidas en Tierra, donde se evidencian líneas continuas, figuras que presentan alto contraste y síntesis en algunas partes, tramado en forma orgánica e impresión en una y dos tintas. Es manifiesta la dificultad de visualización por la mezcla con los textos que se encuentran en el retiro de la página, debido a su impresión en un papel periódico delgado (figura 3). Las tintas muestran irregularidades en la apariencia, como grumos y espacios blancos originados, al parecer, por ser recicladas de otra imprenta. Se trata de una publicación obrera. En todas sus imágenes, el nombre del periódico escrito en minúsculas se destaca por la ubicación, el uso del color con efecto de sombra o el tamaño; hacia la parte inferior derecha o izquierda se puede ver la firma de Luis Efraín Gómez Leal, quien elabora un juego de integración con las cuatro iniciales de su nombre.

Figura 3. Cartel: Colombia contra el fascismo. Autor: Efraín Gómez Leal.

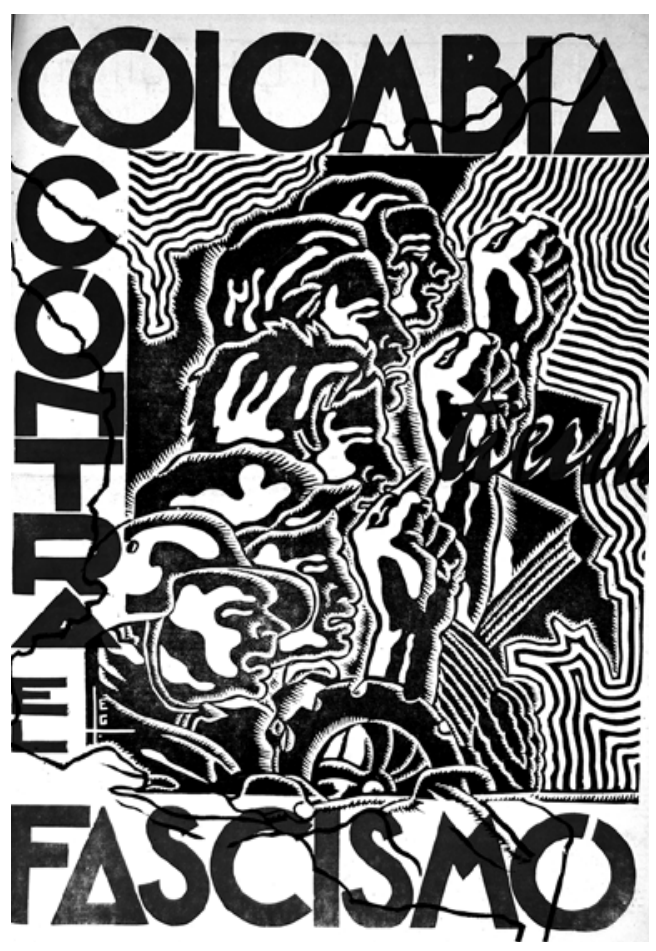

Fuente: Periódico Tierra, marzo de 1938,

Biblioteca Nacional.

Dimensiones: $35 \times 50 \mathrm{~cm}$ 


\section{Descripción}

Cinco personas tienen sus puños cerrados y levantados. Detrás de ellos se ve el mapa de Colombia rodeado de líneas. Sobre la imagen de color azul escrito en rojo dice "tierra". Alrededor de la imagen, un texto en color rojo dice "Colombia ConTRA el FAscisмо", con letras ubicadas a la inversa de las manecillas de un reloj análogo.

El punto visual se ubica en la palabra tierra ubicada al lado derecho del cartel. Después de este elemento, la mirada se dirige a identificar los elementos de la ilustración en color azul y, finalmente, a leer los textos dispuestos en los extremos del cartel. Se observa el mapa de Colombia esbozado en pocas líneas, y en su interior se encuentran algunas figuras algo abstractas que representan a los diferentes miembros de la sociedad; imágenes ubicadas dentro de una línea diagonal ascendente que se inicia en el extremo inferior izquierdo y termina en el extremo superior derecho que se complementa con unos piñones, unos tallos y un libro. Las cuatro primeras figuras, excepto la del soldado, alzan su brazo izquierdo en una actitud de protesta y de lucha. Este cartel representa la unión de sectores de la izquierda colombiana en contra del fascismo. Se evidencia el predominio de la imagen frente al texto. Los rostros vistos de perfil corresponden a soldados, trabajadores y estudiantes cuyo gesto y forma de poner la mano indican actitud de lucha. Al fondo, el contorno del mapa de Colombia se repite como una simulación de ondas. El mapa se sobrepone en ciertos sectores de la frase "Colombia contra el fascisмо" que enmarca la imagen principal.

\section{Comentario}

Este cartel fue el primero que apareció en el periódico y encabezó la edición especial "antifascista de Tierra", en marzo de 1938. En este y los otros carteles de Gómez Leal se manifiesta una relación muy cercana con los carteles antifascistas elaborados en España (ver figuras 4 y 5). Se debe tener en cuenta que la guerra civil española, que se desarrolló entre 1936 y 1939, tuvo una gran difusión entre el pueblo colombiano; no en vano migrantes republicanos huyeron a América e influenciaron el arte y las letras. Por contraste, migrantes nacionalistas también llegaron para acercarse a partidos como el Conservador y ser recibidos de manera abierta por dirigentes como Laureano Gómez.

Figura 4. ¡Unión! ¡Disciplina! ¡Por el socialismo! Cartel del Partido Obrero de Unificación Marxista (роuм). Autor: Carles Fontseré, 1936

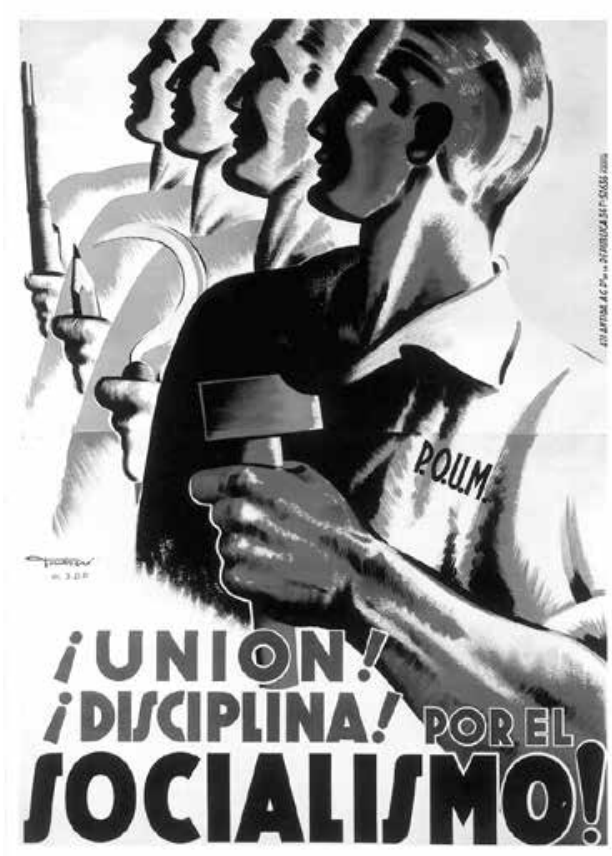


Figura 5. Cartel: 19 julio 1936

Autor: Arturo Ballester, 1936

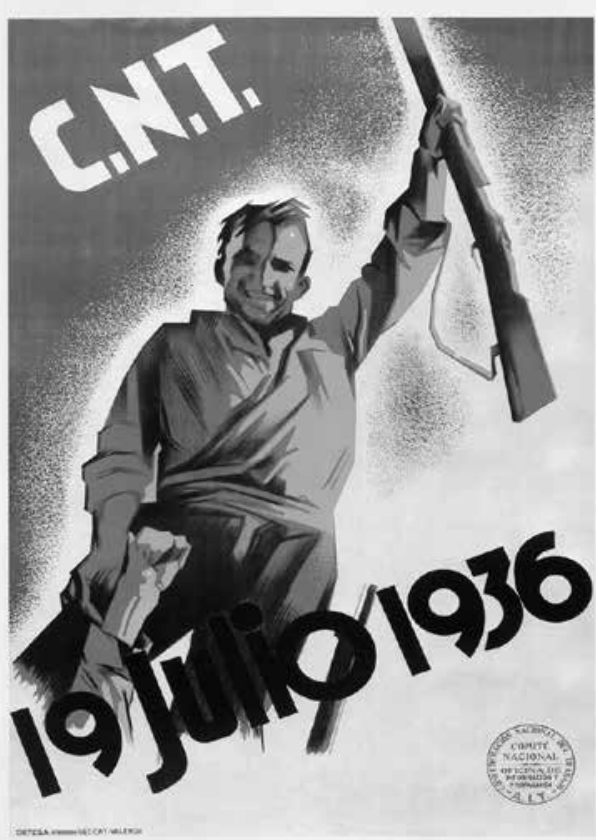

En ese sentido, es necesario añadir que la posición de Colombia ante la adopción de los ideales comunistas era bastante precaria y asimétrica si se considera su complacencia y aceptación de los ideales de derecha, especialmente del "falangismo" franquista, de modo que a la derecha española no le faltaron aliados. En ambos casos, queriendo consolidarse en partidos de masas, los dispositivos de enunciación propugnaban por unidad y disciplina.

Para la década de los años treinta, fascismo y comunismo están en plena construcción y pugna. No hay que olvidar que el fascismo de Mussolini provino de ideas socialistas. La reivindicación común, que salta a la vista en ocasiones, es la del trabajador (figura 6). En el fascismo se trabaja por la propiedad privada; en el comunismo, por la colectiva.
Figura 6. Cartel: $1 .^{\circ}$ de mayo.

Autor: Efraín Gómez Leal

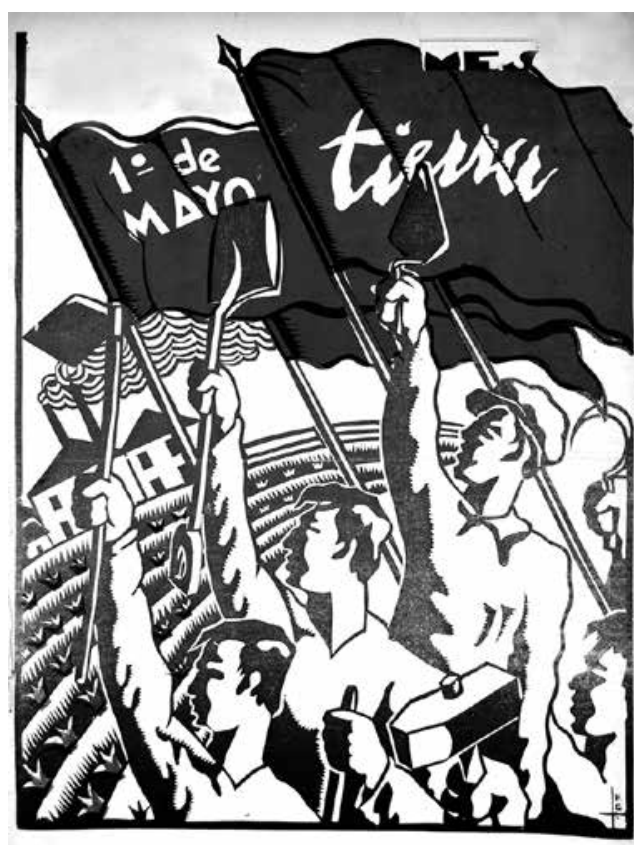

Fuente: Tierra, 1938, Biblioteca Nacional de Colombia. Dimensiones: $35 \times 50 \mathrm{~cm}$

\section{Descripción}

Cinco obreros tienen el brazo derecho levantado; cada uno sostiene un elemento distinto: un azadón, una pala, un palustre, una hoz y un martillo. En el fondo se ve un terreno arado inclinado a la izquierda con un sembrado, en el cual algunas semillas han germinado, (destacadas por el color rojo). Aparece también una fábrica cuyos techos y chimeneas expulsando humo son similares al modelo de fábricas en Colombia (v. figura 7). Sobre la multitud de personas ondean cuatro banderas rojas con sus astas; una dice "1.․ de mayo", otra Tierra, y las otras se encuentran tapadas por las anteriores. La composición, en general, tiene mucha tensión, 
ya que todos sus elementos se insertan en una estructura diagonal. La luz es bastante intensa en ciertos puntos, lo que produce una sombra fuerte y marcada en los rostros y los brazos; por ello, solo se distinguen las siluetas y las herramientas.

La bandera ubicada al lado izquierdo, que dice "1. de mayo", es significativa para recordar el día de los trabajadores, fecha establecida a partir de un hecho histórico: los mártires de Chicago, ciudad donde en 1886 se desarrollaron, por mucho tiempo, marchas y huelgas frente a normas en contra de los trabajadores, como la jornada de trabajo que excedía las ocho horas en malas condiciones y bajos salarios.

Figura 7. Guarda del libro Bavaria: una historia de muchos años

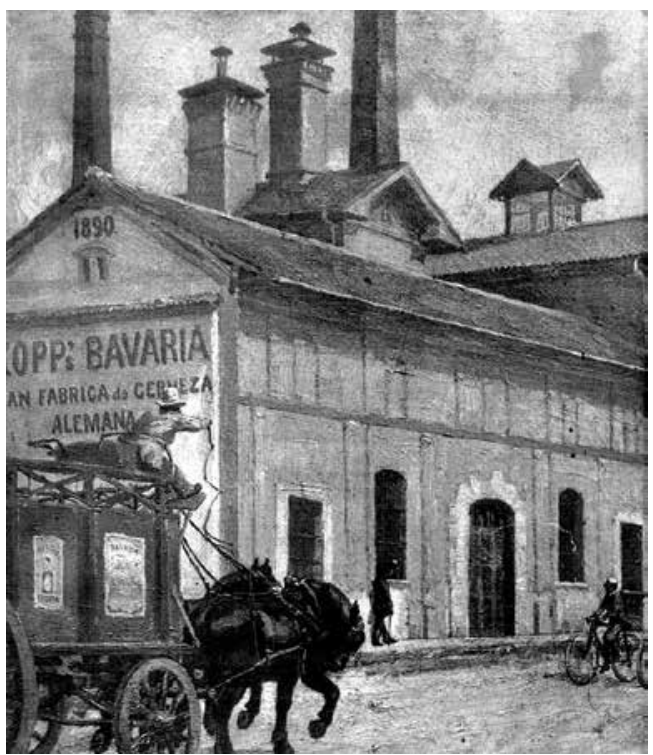

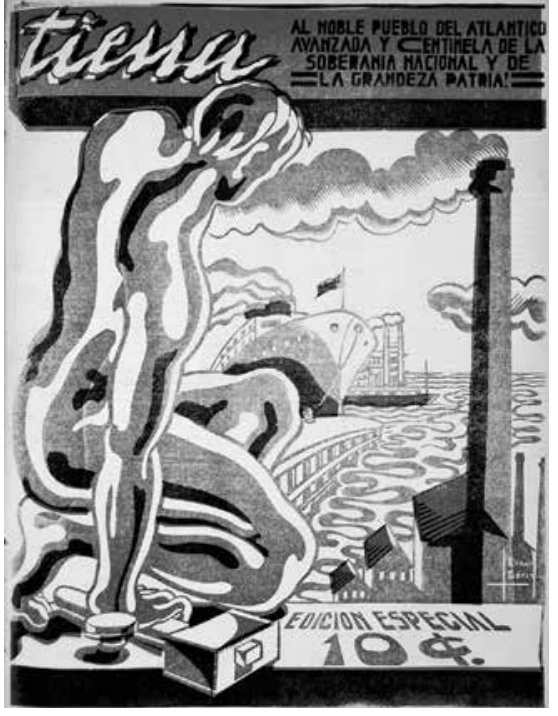

Fuente: Tierra, 1938, Biblioteca Nacional de Colombia. Dimensiones: $35 \times 50 \mathrm{~cm}$

\section{Descripción}

En esta figura se observa un plano general en el cual la composición se sitúa en un puerto. Una figura masculina, desnuda e inclinada se encuentra al lado izquierdo mirando el horizonte, y su mano derecha se apoya en la base de un martillo. A lo lejos se ve una fábrica, algunas casas y un muelle en el océano. Un barco se encuentra llegando al muelle, y detrás otro se aleja. En el cielo se ven algunas nubes de humo provenientes de los barcos y de la chimenea de la fábrica. En la parte superior, sobre una barra roja, dice Tierra, y al lado otro texto afirma: "Al noble pueblo del atlántico avanzada y centinela de la soberanía nacional y de la grandeza patria!". En la parte inferior del cartel, en el costado derecho, aparece: “Edición especial 10 ๕.".

Es evidente la dificultad del registro en impresión de los dos colores, al parecer debido a un trabajo artesanal del método de reproducción, 
que se manifiesta en la aparición de un tercer color, el violeta, por la superposición del rojo y el azul.

Figura 9. Cartel: España defiende la libertad del mundo. Autor: Efraín Gómez Leal.

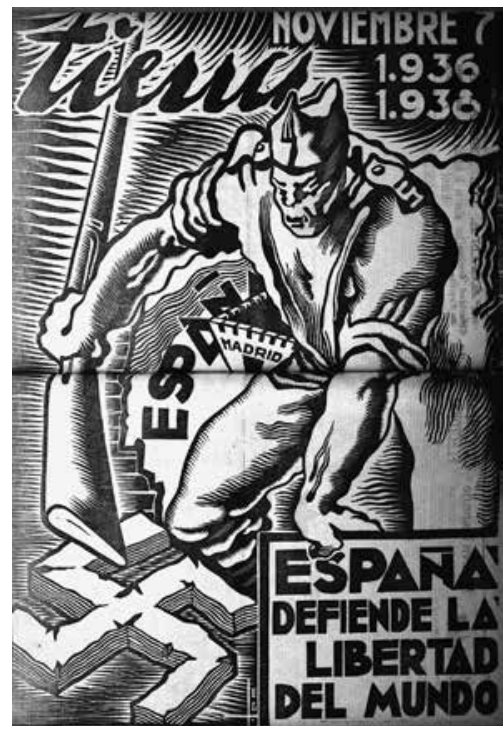

Fuente: Tierra, 1938, Biblioteca Nacional de Colombia. Dimensiones: $60 \times 84 \mathrm{~cm}$

\section{Descripción}

Un soldado se encuentra de pie un poco inclinado hacia delante. Es un soldado que tiene sus mangas remangadas como un obrero y en su mano derecha sostiene un fusil con el que está golpeando una esvástica en relieve y con algunas grietas a sus pies. Detrás de él se ve el mapa de España en el que se resalta a Madrid como una fortaleza y aparece un texto: "España", en la parte de atrás. Con su mano izquierda se apoya sobre un cuadro de texto que reza "España defiende la libertad del mundo". La esvástica se encuentra en el suelo. En la parte superior del cartel dice Tierra y al lado de este texto otro dice "Noviembre 7 1936-1938".
La estética de estos carteles bien puede basarse en moldes calcados de los carteles europeos, tanto de derecha como de izquierda. Recordemos que el fascismo apeló también a las masas y a los trabajadores. Ese es un punto de convergencia con el comunismo. De allí que haya similitudes que se distancian fundamentalmente cuando la hoz y el martillo aparecen en manos de obreros.

\section{Conclusiones}

Es evidente la interpretación positiva de los ideales comunistas en el periódico Tierra, no solo en los artículos sino también en los símbolos e imágenes que presenta. Las imágenes y colores expuestos en los cuatro carteles que se analizan y muestran en este artículo buscan hacer partícipes a los lectores de un objetivo: la toma del poder para los trabajadores. De allí que como dispositivo de enunciación, Tierra, conllevara un discurso completamente afín al comunismo, orientara comportamientos que garantizaran la unidad de partido $y$, por último pero no menos importante, promoviera la identificación sin equívocos con una estética que reconociera como sujeto al trabajador y lo incorporara en un universo simbólico sólido, fácil de reconocer y de recordar. Los carteles impresos en el periódico con la hoz y el martillo, la pala, el palustre, las armas y en especial el acto en que se golpea la esvástica nazi como símbolo de la contraposición a los ideales fascistas que se apoderaban del mundo calan en la memoria gracias al uso de altos contrastes y de figuras prominentes de alta recordación. 
El color rojo, símbolo representativo del movimiento comunista, se emplea en los carteles impresos por este periódico (con excepción de aquel en que se golpea la esvástica nazi). Quizás este uso del color sea una de las razones por las cuales se llegó a comparar el comunismo con el movimiento liberal, en cuanto este último también adoptó el rojo para diferenciarse de los conservadores.

Después de la revisión se plantea que las imágenes de Gómez Leal contribuyen a la construcción de la identidad de partido en el país. Elabora el tema de la clase trabajadora destacando su espíritu de lucha, de insubordinación. En los textos se encuentran de manera reiterada palabras como camarada, manifestación, antifascista, sindical, compañeros, etc.: se construye un léxico que identifica a la comunidad que el diario convoca a lo largo de todas las ediciones, desde 1932 hasta 1939.

Como dispositivo de enunciación, Tierra busca coherencia discursiva en lo verbal y en lo gráfico; apela a recursos de fácil identificación y a la reiteración; asocia realidades locales con nacionales e internacionales, describiendo los hechos históricos en sus artículos pero también en sus carteles. Con ello, intenta, entonces, jugar con un doble propósito: unidad discursiva en lo político y como programa ideológico (local, nacional e internacional, al considerar que el comunismo se caracteriza por ser un proyecto internacionalista); y unidad discursiva en lo semántico, como dispositivo de enunciación que completa sus reglas de juego al apelar a lo gráfico y a lo verbal.

\section{REFERENCIAS}

Archila, M. (1992). Cultura e identidad obrera: Colombia 1910-1945. Bogotá: Cinep.

Deleuze, G. (1990). ¿Qué es un dispositivo? En Michel Foucault, filósofo (pp. 155-163). Barcelona: Gedisa,

Koselleck, R. (1993). Representación, acontecimiento y estructura. En Futuro pasado: para una semántica de los tiempos históricos (pp. 141-152). Barcelona: Paidós,

López, P. (2009). Cartel ilustrado en Colombia: década 1930-1940. Bogotá: Universidad de Bogotá Jorge Tadeo Lozano.

Medina, A. (1995). El arte colombiano de los años veinte y treinta. Bogotá: Colcultura.

Troconi, G. (2010). Diseño gráfico en México. 100 años. 1900-2000. México: Artes de México. 